www.jmscr.igmpublication.org

Index Copernicus Value: 79.54

ISSN (e)-2347-176x ISSN (p) 2455-0450

crossref DOI: https://dx.doi.org/10.18535/jmscr/v7i6.125

\title{
A Study on Substance Abuse among Professional College Students of Northern Western Rajasthan
}

\author{
Authors \\ Aditya Kochar ${ }^{1}$, Abhimanyu Agarwal ${ }^{2 *}$, Sushil Kumar Sharma ${ }^{3}$, Akanksha Arya ${ }^{4}$, \\ Sanjay Kumar Kochar \\ ${ }^{1,2}$ Third MBBS, S P Medical College, Bikaner, Rajasthan, India \\ ${ }^{3}$ Intern, S P Medical College, Bikaner, Rajasthan, India \\ ${ }^{4}$ Final MBBS, S P Medical College, Bikaner, Rajasthan, India \\ ${ }^{5}$ Senior Professor, Department of General Medicine, S P Medical College, Bikaner, Rajasthan, India \\ *Correspondence Author
}

Abhimanyu Agarwal

Third MBBS, S P Medical College, Bikaner, Rajasthan, India

\begin{abstract}
Background: Substance abuse is a growing problem in the world. Millions of people throughout the world are abusing substances such as alcohol, nicotine, cocaine, methamphetamine, morphine, marijuana, heroin and many others.

Methods: This is a cross-sectional survey with the use of questionnaires to estimate the prevalence of substance abuse among the professional college students in Bikaner Rajasthan. The study was conducted during 2018-19 by using self-administered questionnaires that included demographic parameters and questions about substance abuse.

Results: The total prevalence of substance abuse among professional college students was found to be 29.5\%. Male students had significantly higher prevalence of substance abuse as compared to female counterparts (43.26\% versus $7.74 \%$ respectively). The most common substance being abused was Alcohol (27.75\%) followed by tobacco (9.25\%).

Conclusion: Prevalence of substance abuse among professional college students is high and causes significant problems in this population; therefore there is necessity of targeted interventions to reduce this huge burden.
\end{abstract}

Keywords: substance abuse, Professional college, Student.

\section{Introduction}

Substance abuse is a growing problem in the world. Millions of people throughout the world are abusing substances such as alcohol, nicotine, cocaine, methamphetamine, morphine, marijuana, heroin and many others. ${ }^{1}$
By definition, a substance abuse refers to injurious or harmful use of psychoactive substances that include alcohol and illegal drugs. The psychoactive substances abusers have always a strong desire to repeat the dose. They find difficulty to control the use of these substances or may suffer from withdrawal effects. ${ }^{2}$ There are 
many potential risk factors that escalate the risk of substances abuse. These include genetic factors, family environment, lack of parental attachment, outside environment and mental health. ${ }^{3}$

Adolescence is the critical period when the first initiation of substance abuse takes place. Among the adolescents, professional students are particularly vulnerable due to various reasons like academic pressure, temptation by peer groups, the lure of popularity and identification and easy availability of many such substances like tobacco (cigarettes) and other psychoactive drugs. Changing social values, globalization, violence and conflict ridden cultures in nations across the world have undoubtedly added tremendous stress on all human beings and especially adolescents and young adult population making them vulnerable to substance abuse. Research has shown that exposure to violence with armed conflict is a potential risk factor not only for posttraumatic stress disorders and psychosocial problems but also for indulgence in substance abuse. $^{4}$

\section{Material and Methods}

This is a cross-sectional survey with the use of questionnaires to estimate the prevalence of substance abuse among the professional college students in Bikaner Rajasthan. The study was conducted during 2018-19 by using selfadministered questionnaires that included demographic parameters and questions about substance abuse.

Directly related questions concerning the onset of substance use, the type of substances, reasons for abuse, disadvantages of substance use like absent from college and medical problems associated with abuse, knowledge about the distribution of the substances, role of school surrounding in substance abuse were all included in the questionnaire. 400 college students were selected by simple random sampling technique.

Data was recorded on a Performa. The data analysis was computer based; Epi-info software was used for analysis. For categoric variables chisquare test was be used. $p$-value $<0.05$ will be considered as significant.

\section{Observation}

Table 1: Personal Information

\begin{tabular}{|c|c|c|c|c|c|c|c|}
\hline S. No. & Details & \multicolumn{2}{|c|}{ Males } & \multicolumn{2}{|c|}{ Females } & \multicolumn{2}{|c|}{ Total } \\
\hline & & $\mathrm{No}(245)$ & $\%$ & No.(155) & $\%$ & $\operatorname{No}(400)$ & $\%$ \\
\hline \multirow[t]{4}{*}{1} & Age(Yrs) & & & & & & \\
\hline & $<20$ & 78 & 31.84 & 41 & 26.45 & 119 & 29.75 \\
\hline & $20-24$ & 164 & 66.94 & 113 & 72.90 & 277 & 69.25 \\
\hline & $>24$ & 3 & 1.22 & 1 & 0.65 & 4 & 1.00 \\
\hline \multirow[t]{3}{*}{2} & Education & & & & & & \\
\hline & $<=2$ years & 112 & 45.71 & 31 & 20.00 & 143 & 35.75 \\
\hline & $>2$ years & 133 & 54.29 & 124 & 80.00 & 257 & 64.25 \\
\hline \multirow[t]{4}{*}{3} & Residence & & & & & & \\
\hline & Rural & 137 & 55.92 & 56 & 36.13 & 193 & 48.25 \\
\hline & Urban & 55 & 22.45 & 70 & 45.16 & 125 & 31.25 \\
\hline & Mixed & 47 & 19.18 & 23 & 14.84 & 70 & 17.50 \\
\hline
\end{tabular}

Table 2: Substance abuse

\begin{tabular}{|l|l|c|c|c|c|c|c|c|}
\hline S. No. & Details & \multicolumn{2}{|c|}{ Males } & \multicolumn{2}{c|}{ Females } & \multicolumn{2}{c|}{ Total } & \multicolumn{1}{c|}{$\begin{array}{c}\text { p- } \\
\text { value }\end{array}$} \\
\hline \multicolumn{2}{|l|}{} & So(245) & $\%$ & No(155) & $\%$ & Nos. & 0.087 \\
\hline & No & & & & & & \\
\hline & Yes & 217 & 88.57 & 146 & 94.19 & 363 & 90.75 \\
\hline 2 & Water Smoking & 28 & 11.43 & 9 & 5.81 & 37 & 9.25 & \\
\hline & No & & & & & & & 0.212 \\
\hline & Yes & 233 & 95.10 & 152 & 98.06 & 385 & 96.25 \\
\hline 3 & If yes, Type of water smoking & 12 & 4.90 & 3 & 1.94 & 15 & 3.75 \\
\hline & Hukkah & 6 & 50.00 & 3 & 1000.00 & 9 & 60.00 \\
\hline
\end{tabular}




\begin{tabular}{|l|l|c|c|c|c|c|c|c|} 
& Chillum & 3 & 25.00 & 0 & 0.00 & 3 & 20.00 & \\
\hline & Other & 3 & 25.00 & 0 & 0.00 & 3 & 20.00 & \\
\hline 4 & Alcohol consumption & & & & & & & 0.001 \\
& Never & 142 & 57.96 & 147 & 94.84 & 289 & 72.25 \\
\hline & Occasionally & 71 & 28.98 & 8 & 5.16 & 79 & 19.75 \\
\hline & Sometimes & 24 & 9.80 & 0 & 0.00 & 24 & 6.00 \\
\hline & Often & 5 & 2.04 & 0 & 0.00 & 5 & 1.25 \\
\hline & Daily & 3 & 1.22 & 0 & 0.00 & 3 & 0.75 & \\
\hline
\end{tabular}

Prevalence of smoking in male was $11.43 \%$ and in female was $5.81 \%$. Smoking was insignificantly higher in male as compare to female. Water smoking was also insignificantly higher in male
$(4.90 \%)$ as compare to female $(1.94 \%)$. Alcohol consumption was significantly higher in male $(42.03 \%)$ as compare to female $(5.16 \%)$.

Table 3. Prevalence of substance abuse

\begin{tabular}{|l|c|c|c|c|c|c|c|}
\hline \multirow{2}{*}{$\begin{array}{l}\text { Substance } \\
\text { abuse }\end{array}$} & \multicolumn{2}{|c|}{ Male } & \multicolumn{2}{c|}{ Female } & \multicolumn{2}{c|}{ Total } & $\mathrm{p}$-value \\
\cline { 2 - 8 } & No.(n=245) & Percentage & No.(n=155) & Percentage & No.(n=400) & Percentage & \multirow{2}{*}{0.001} \\
\hline Used Yes & 106 & 43.26 & 12 & 7.74 & 118 & 29.5 & 70.5 \\
\hline Used No & 139 & 56.74 & 143 & 82.26 & 182 & \\
\hline
\end{tabular}

The prevalence of substance abuse was significantly higher in male $(43.26 \%)$ as compared to female $(7.74 \%)$.

\section{Discussion}

People's life can be influenced by lifestyle, level of education, health, social relations, economic status and religious belief. The substantial changes that an individual experiences in adolescence age are considered as most crucial and difficult period in individuals' life. At this particular age, individuals like to get independence, so they do such thing that may even dangerous not only for themselves but for society as well.

Substance abuse is the most common social calamity practiced during adolescence. The major aim of this study was to evaluate the prevalence and patterns of substance use among professional college students in Bikaner.

In our research study the overall prevalence of substance abuse among professional college students was found to be $29.5 \%$.

PR Kokiwar and GRS Jogdand ${ }^{5}$ in their study found an overall prevalence of $32.7 \%$ for substance abuse among male adolescents in urban slums in Karim Nagar, Andhra Pradesh. This prevalence is similar to that observed in our study. However it was lower than as reported by Sarangi
L et $\mathrm{al}^{6}$ and Juyal $\mathrm{R}$ et al ${ }^{7}$ (Dehradun) who in their studies found the overall prevalence of substance abuse to be $49.5 \%$ and $58.7 \%$ respectively. This higher prevalence found by in their studies could be attributed to the fact that chewing tobacco was included in their study which is frequently taken by children in that part of India. However the use of chewing tobacco is not so much prevalent in students of Bikaner. However our results were much more than Margoob $\mathrm{M}$ et $\mathrm{al}^{8}$ who found an overall prevalence of $2 \%$ for drug abuse in patients attending the OPDs of Psychiatric Disease Hospital in Kashmir Valley. The reason being that while the study done was a Hospital based on patients attending OPDs and does not reflect the overall prevalence in community and secondly it was done on patients attending for Psychiatric diseases and not for treatment of substance abuse.

Sinha et $\mathrm{al}^{9}$ in their study reported a prevalence of $19.4 \%$ for tobacco smoking in school students in Bihar. This was higher to the prevalence of tobacco smoking we found in our study.

\section{Conclusion}

The substance abuse is not a simple problem but a social pathology whose roots are deeply penetrated in the society. Involvement in 
substance abuse can lead to depression and vice versa. This can form a vicious cycle and thus ruin the lives of most productive part of our community that is young adolescent students.

We recommend that more and more IEC (Information, Education and Communication) activities be carried out to spread the knowledge about substance abuse and its prevention in the society.

We also recommend that more and more drug dependence treatment and counselling centers be formed at all district levels so that they can provide a comprehensive package essential to treat and counsel the people involved in this social evil.

\section{References}

1. Hamed Al-Alawi AS, Shaikh J. Prevalence of Substance Abuse among the School Students in Al-Dhahirah Governorate, Sultanate of Oman. Madridge J Nurs. 2018; 3(1): 118-123.

2. World Health Organization. Substance abuse. Last accessed 28 May 2019.

3. Das JK, Salam RA, Arshad A, Finkelstein Y, Bhutta ZA. Interventions for adolescent substance abuse: An overview of systematic reviews. Journal of Adolescent Health. 2016; 59(4): 61-75.

4. Baba TA, Ganai AM, Qadri SS, Margoob MA, Iqbal QM, Khan ZA. An epidemiological study on substance abuse among college students of North India (Kashmir valley). Int J Med Sci Public Health 2013; 2:562-567.

5. Kokiwar PR, Jogdand GR. Prevalence of substance use among male adolescents in an urban slum area of Karimnagar district, Andhra Pradesh. Indian J Public Health. 2011;55(1):42-45.
6. Sarangi L, Acharya HP, Panigrahi OP. Substance Abuse Among Adolescents in Urban Slums of Sambalpur. Indian $\mathbf{J}$ Community Med. 2008; 33(4): 265-267.

7. Juyal R, Bansal R, Kishore S, Negi KS, Chandra R, Semwal J. Substance abuse among Intercollege students in District Dehradun. Indian J Community Med 2006;31:10-127.

8. Margoob MA, Dutta KS. Drug abuse in Kashmir - experience from a psychiatric diseases hospital. Indian $\mathbf{J}$ Psychiatry. 1993;35(3):163-5.

9. Sinha DN. Tobacco and noncommunicable diseases. Indian J Public Health. 2004,48:111-115. 